The joints studied are:

- The wrist and hand

- The elbow

- The shoulder

- The ankle and foot

- The knee

- and the hip

100 sections were performed, we presented them together with images showing ther normal corresponding musculoskeletal anatomy, the valid positioning of the probe, and also an annotated schema corresponding to each section. We give here below the example of a section illustrating a cross-section of flexor digitorum superficialis and profondus tendons

Conclusions: We hope that we give to rheumatologists a simple tool to recall and standardize the practice of musculoskeletal ultrasound. We intend to enrich it, in the future, with the pathological images and interventional ultrasound videos.

Disclosure of Interest: None declared

DOI: 10.1136/annrheumdis-2017-eular.4514

\section{AB1042 DYNAMIC CONTRAST-ENHANCED MAGNETIC RESONANCE IMAGING IN A RANDOMIZED PLACEBO-CONTROLLED RHEUMATOID ARTHRITIS TRIAL - IMPACT OF APPLYING JOINT COVERAGE QUALITY CRITERIA}

M.B. Axelsen $^{1}$, H. Bliddal ${ }^{2}$, L.T.H. Jacobssen ${ }^{3}$, M.S. Hansen ${ }^{4}$, A. Dudek ${ }^{5}$, M. Rell-Bakalarska ${ }^{6}$, M. Boesen ${ }^{7}$, J. Stefanek ${ }^{8}$, B. Sundman-Engberg ${ }^{9}$ M. Østergaard ${ }^{1} .{ }^{1}$ Copenhagen Center for Arthritis Research, Center for Rheumatology and Spine Diseases, Centre of Head and Orthopedics, Rigshospitalet; ${ }^{2}$ The Parker Institute, Hospital Frederiksberg-Bispebjerg, Copenhagen, Denmark; ${ }^{3}$ Department of Rheumatology and Inflammation Research, Sahlgrenska Academy at University of Gothenburg, Gothenburg, Sweden; ${ }^{4}$ Center for Rheumatology and Spine Diseases, Rigshospitalet, Gentofte, Denmark; ${ }^{5}$ Centrum Medyczne MEDENS S.C., Wojewodztwo slaskie; ${ }^{6}$ Rheumatology, Rheumatology, Poland, Poland; ${ }^{7}$ Department of Radiology, The Parker Institute, Hospital Frederiksberg-Bispebjerg, Copenhagen, Denmark; ${ }^{8}$ UCB Biosciences GmbH, Monheim, Germany; ${ }^{9}$ UCB Pharma AB, Stockholm, Sweden

Background: Dynamic contrast-enhanced MRI (DCE-MRI) has been proposed for evaluating treatment response in RA. In a 16-week anti-TNF trial, DCE-MRI measures of inflammation analyzed for regions of interest (ROIs) covering MCP joints $2-5$ and PIP joints $2-5$ detected improvements at week 16 , but not at earlier time point ${ }^{1}$.

Objectives: To investigate if solely analyzing joints fulfilling predefined MRI quality criteria for joint visualization would increase the responsiveness and discrimination between treatments of DCE-MRI.

Methods: Patients with active RA despite stable DMARD therapy for $\geq 12$ weeks were randomized 2:1 to certolizumab pegol (CZP) or 2 weeks of placebo (PBO) followed by CZP (CZP+PBO). MRIs were obtained at weeks 0 (baseline), 1, 2, 4,8 and 16 . Only joints fulfilling $\mathrm{MRI}$ joint quality criteria $(\geq 3 \mathrm{MCP} / \geq 2 \mathrm{PIP}$ joint slices including the distal and/or the proximal bone of the joint and part of the joint cavity) were included in analyses. ROls covering each joint were analyzed for number of enhancing voxels (Nvoxel), initial rate of enhancement (IRE) and maximum enhancement (ME) using the DYNAMIKA software (Image Analysis, UK).

Results: For 38 (CZP: 26 ; PBO+CZP: 12) of the 40 randomized patients, $>1$ joint fulfilled the quality criteria at baseline. 31 MCP2, 28 MCP3, 23 MCP4, 7 MCP5, 29 PIP2, 29 PIP3, 28 PIP4 and 12 PIP5 joints were included. No individual joints showed significant changes over time or differences between groups. Analyses by joint group (MCP2-4 and PIP2-4) had few data available. Nvoxel and ME decreased numerically, but not significantly, for PIP2-4.

Conclusions: There were no statistically significant changes in DCE-MRI on joint level or joint group level or between groups. Applying strict joint coverage quality criteria compromises the statistical power of the DCE-MRI analyses underlining the importance of standardization of the method.
References:

[1] Østergaard. Arthritis Rheum 2014;66(Suppl. 10):518

Disclosure of Interest: M. B. Axelsen Grant/research support from: UCB Nordic funded the study, $\mathrm{H}$. Bliddal Grant/research support from: UCB Nordic, L. T. H. Jacobssen Consultant for: Abbvie, Celegen, MSD, Novartis and UCB, M. Hansen: None declared, A. Dudek: None declared, M. Rell-Bakalarska: None declared, M. Boesen Consultant for: Chairman of the clinical advisory board Image Analysis, LTD London, J. Stefanek: None declared, B. SundmanEngberg: None declared, M. Østergaard Grant/research support from: and/or speaking/consultant fees: Abbvie, BMS, Boehringer-Ingelheim, Celgene, Eli-Lilly, Centocor, GSK, Hospira, Janssen, Merck, Mundipharma, Novartis, Novo, Orion, Pfizer, Regeneron, Schering-Plough, Roche, Takeda, UCB, and Wyeth

DOI: 10.1136/annrheumdis-2017-eular.1946

\section{AB1043 RHEUMATOID FACTOR ISOTYPES - STILL AN USEFUL TOOL IN THE DIAGNOSIS OF RHEUMATOID ARTHRITIS?}

M. Guerra ${ }^{1}$, R. Vieira ${ }^{1}$, A.P. Cruz ${ }^{2}$, T. Videira ${ }^{1}$, P. Pinto ${ }^{1} .{ }^{1}$ Department of Rheumatology; ${ }^{2}$ Department of Clinical Pathology, Centro Hospitalar Vila Nova de Gaia/Espinho, Vila Nova de Gaia, Portugal

Background: Rheumatoid factor (RF) and anti-citrullinated peptide antibodies (ACPA) are key serologic markers in the diagnosis of Rheumatoid Arthritis (RA) included in the 2010 ACR/EULAR diagnostic criteria. Determination by enzymelinked immunosorbent assay (ELISA) allows RF isotypes' quantification (IgG, $\lg A$ and IgM), improving diagnostic accuracy ${ }^{1,2}$.

Objectives: To assess the clinical value of RF-lgG/lgA/lgM (ELISA) in the diagnosis of RA, in comparison to RF-IgM (nephelometry).

Methods: A population of RA outpatients fulfilling the 2010 ACR/EULAR diagnostic criteria was cross-sectionally evaluated. Data on demographic and clinical characteristics was collected. RF-lgG / IgA / IgM (ELISA, Orgentec $\left.{ }^{\circledR}\right)$, RFIgM (nephelometry, Siemens ${ }^{\circledR}$ ) and ACPA-IgG (ELiA, ThermoFisher ${ }^{\circledR}$ ) were measured. Values three times or more above the upper limit of normal were considered high-positive (in agreement to 2010 ACR/EULAR diagnostic criteria).

Results: A total of 87 patients (70.1\% female) were included, with a mean (SD) age of 57.3 (12.29) years. Median time of disease evolution was 6 years, ranging from 0 to 37 years. Erosions were present in $50.6 \%(\mathrm{~N}=44)$. RF-ELISA was positive (at least one isotype increased) in $85.1 \%(\mathrm{~N}=74)$; the most frequent isotype was $\operatorname{lgM}(70.1 \% ; \mathrm{N}=61)$ and the most frequent combination was $\operatorname{lgG}$, $\lg \mathrm{A}$ and IgM positivity $(46.0 \% ; \mathrm{N}=40)$ (table1). FR-nephelometry and ACPA were positive in $58.6 \%(\mathrm{~N}=51)$ and $47.1 \%(\mathrm{~N}=41)$, respectively.

Comparing the two RF methods, $56.3 \%(\mathrm{~N}=49)$ were both RF-nephelometry and RF-ELISA positive; $28.7 \%(\mathrm{~N}=25)$ were RF-ELISA positive and RF-nephelometry negative, and only $2.3 \%(\mathrm{~N}=2)$ verified the opposite $(\mathrm{p}=0.001)$. As for RF highpositivity, $4.6 \%(\mathrm{~N}=4)$ of the 87 patients were only RF-nephelometry high-positive, $9.2 \%(\mathrm{~N}=8)$ only RF-ELISA high-positive and $34.5 \%(\mathrm{~N}=30)$ both high-positive $(p<0.001)$.

In the RF-nephelometry negative population ( $\mathrm{N}=36)$, ACPA and RF-ELISA were both positive in $11.1 \%(\mathrm{~N}=4)$. Only $8.3 \%(\mathrm{~N}=3)$ were solely ACPA positive and $58.3 \%(\mathrm{~N}=21)$ solely RF-ELISA positive, however without statistical significance. Considering the ACPA negative population $(\mathrm{N}=46), 32.6 \%(\mathrm{~N}=15)$ were both $\mathrm{RF}$

Table 1. Frequencies of RF-ELISA isotypes' profiles

\begin{tabular}{|c|c|c|}
\hline Profile & $\mathrm{n}$ & $\%$ \\
\hline $\lg G-\lg A-\lg M-$ & 13 & 14,9 \\
\hline $\lg G+\lg A-\lg M-$ & 1 & 1,1 \\
\hline $\lg G+\lg A+\lg M_{-}$ & 4 & 4,6 \\
\hline $\lg G_{+} \lg A ? \lg M_{+}$ & 1 & 1,1 \\
\hline $\lg G+\lg A-\lg M+$ & 12 & 13,8 \\
\hline $\lg G+\lg A+\lg M+$ & 40 & 46,0 \\
\hline $\lg G-\lg A+\lg M_{+}$ & 5 & 5,7 \\
\hline $\lg G-\lg A-\lg M_{+}$ & 3 & 3,4 \\
\hline $\lg G-\lg A+\lg M-$ & 8 & 9,2 \\
\hline
\end{tabular}

Abstract AB1042 - Table 1. Baseline values of and changes in DCE-MRI parameters for MCP2-4 and PIP2-4

\begin{tabular}{|c|c|c|c|c|c|c|}
\hline & Baseline & Change week 0 -week 1 & Change week 0 -week 2 & Change week 0 -week 4 & Change week 0 -week 8 & Change week $0-$ week 16 \\
\hline Median change [number] & $\mathrm{PBO}+\mathrm{CZP} / \mathrm{CZP}$ & $\mathrm{PBO}+\mathrm{CZP} / \mathrm{CZP}$ & $\mathrm{PBO}+\mathrm{CZP} / \mathrm{CZP}$ & $\mathrm{PBO}+\mathrm{CZP} / \mathrm{CZP}$ & $\mathrm{PBO}+\mathrm{CZP} / \mathrm{CZP}$ & $\mathrm{PBO}+\mathrm{CZP} / \mathrm{CZP}$ \\
\hline \multicolumn{7}{|l|}{ Nvoxel } \\
\hline MCP2-4 & $\begin{array}{l}295 / 131 \\
{[5] /[12]}\end{array}$ & $\begin{array}{c}\mathrm{NA} /-503 \\
{[1] /[4]}\end{array}$ & $62 / 0$ & $\begin{array}{l}\mathrm{NA} / 0 \\
{[1] /[5]}\end{array}$ & $\begin{array}{l}90 / 53 \\
{[2] /[4]}\end{array}$ & $\begin{array}{c}\mathrm{NA} /-473 \\
{[1] /[5]}\end{array}$ \\
\hline PIP2-4 & $\begin{array}{c}108 / 144 \\
{[8] /[15][3] /[6]}\end{array}$ & $\begin{array}{l}-35 / 0 \\
{[5] /[7]}\end{array}$ & $\begin{array}{c}-56 /-12 \\
{[5] /[4]}\end{array}$ & $\begin{array}{l}-80 /-75 \\
{[7] /[10]}\end{array}$ & $\begin{array}{c}-69^{*} / 10 \\
{[5] /[8]}\end{array}$ & $-32 /-12$ \\
\hline \multicolumn{7}{|c|}{ 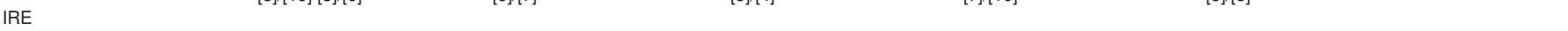 } \\
\hline MCP2-4 & $\begin{array}{c}0.000 / 0.004 \\
{[4] /[9]}\end{array}$ & $\begin{array}{c}\mathrm{NA} / 0.000 \\
{[0] /[3]}\end{array}$ & $\begin{array}{c}0.006 / 0.00 \\
{[2] /[2]}\end{array}$ & $\begin{array}{c}\mathrm{NA} / 0.000 \\
{[0] /[4]}\end{array}$ & $\begin{array}{c}0.273 /-0.023 \\
{[2] /[2]}\end{array}$ & $\begin{array}{c}\mathrm{NA} / 0.002 \\
{[0] /[5]}\end{array}$ \\
\hline PIP2-4 & $\begin{array}{c}0.013 / 0.006 \\
{[8] /[10]}\end{array}$ & $\begin{array}{c}-0.002 /-0.001 \\
{[2] /[3]}\end{array}$ & $\begin{array}{c}0.000 / 0.001 \\
{[5] /[5]}\end{array}$ & $\begin{array}{c}0.003 / 0.000 \\
{[5] /[3]}\end{array}$ & $\begin{array}{c}0.014^{\star} / 0.000 \\
{[5] /[5]}\end{array}$ & $\begin{array}{c}0.000 / 0.023 \\
{[4] /[2]}\end{array}$ \\
\hline \multicolumn{7}{|l|}{ ME } \\
\hline PIP2-4 & $\begin{array}{c}0.013 / 0.006 \\
{[8] /[10]}\end{array}$ & $\begin{array}{c}-0.002 /-0.001 \\
{[2] /[3]}\end{array}$ & $\begin{array}{c}0.000 / 0.001 \\
{[5] /[5]}\end{array}$ & $\begin{array}{c}0.003 / 0.000 \\
{[5] /[3]}\end{array}$ & $\begin{array}{c}0.014^{\star} / 0.000 \\
{[5] /[5]}\end{array}$ & $\begin{array}{c}0.000 / 0.023 \\
{[4] /[2]}\end{array}$ \\
\hline PIP2-4 & $\begin{array}{c}1.76 / 1.99 \\
{[8] /[10]}\end{array}$ & $\begin{array}{c}-0.16 /-0.30 \\
{[2] /[3]}\end{array}$ & $\begin{array}{c}-0.17 / 0.02 \\
{[5] /[5]}\end{array}$ & $\begin{array}{c}-0.23 / 0.03 \\
{[5] /[3]}\end{array}$ & $\begin{array}{c}-0.02 /-0.01 \\
{[5] /[5]}\end{array}$ & $\begin{array}{c}-0.19 /-0.12 \\
{[4] /[2]}\end{array}$ \\
\hline
\end{tabular}


positive; $45.7 \%$ ( $\mathrm{N}=21$ ) were RF-ELISA positive and RF-nephelometry negative and $4.3 \%(N=2)$ the opposite, without a statistical significance.

Conclusions: ELISA is superior to nephelometry detecting RF in patients with $\mathrm{RA}$, as also in quantifying high-positive values.

References:

[1] Routine measurement of $\operatorname{lgM}, \lg G$, and $\lg A$ rheumatoid factors: high sensitivity, specificity, and predictive value for rheumatoid arthritis. Swedler W, Wallman J, Froelich CJ, Teodorescu M. J Rheumatol, 1997 Jun;24(6):1037-44.

[2] Is rheumatoid factor still a superior test for the diagnosis of rheumatoid arthritis? Singh U, Vishwanath A, Verma PK et al. Rheumatol int, 2010 June; 30(8):1115-9.

Disclosure of Interest: None declared

DOI: 10.1136/annrheumdis-2017-eular.2606

\section{AB1044 EVALUATION OF A FLUOROENZYME IMMUNOASSAY (ELIA-CTD) IN THE SCREENING OF PATIENTS SUSPECTED FOR AUTOIMMUNE CONNECTIVE TISSUE DISEASES}

M. Elkhalifa ${ }^{1}$, R. Abdulhadi ${ }^{1}$, H. Ramadan ${ }^{1}$, S. Barrientos ${ }^{1}$, S. Saleh ${ }^{1}$, O. Alsaed ${ }^{2}$, A.-W. Al-Allaf ${ }^{2} .{ }^{1}$ Laboratory Medicine and Pathology; ${ }^{2}$ Medicine, Hamad Medical Corporation, Doha, Qatar

Background: Detection of auto-antibodies directed against nuclear antigens (antinuclear antibodies or ANA) have important diagnostic and prognostic implications in connective tissue diseases (CTD). The conventional indirect immunofluorescence assay on HEp-2 cell line (ANA-IIF) is the most commonly used method to detect ANA. The ANA-IIF can be labor intensive and suffers from lack of specificity.

Objectives: To evaluate the utility of a new fluoroenzyme Immunoassay "EliACTD" as an alternative for screening patients suspected for autoimmune connective tissue diseases.

Methods: Sixteen Hundread (1600) consecutive patients' sera submitted for anti-nuclear antibodies were tested using the ANA-IIF (Diasorin S.P.A, Saluggia, Italy) and the new EliA-CTD screen (Phadia GmbH, Frieiburg, Germany). ANA testing was ordered by both primary and secondary care physicians. The EliACTD screening assay is a fluoroenzyme immunoassay which is performed on the Phadia-250 automated platform. The EliA-CTD assay contains ANA-targeted recombinant antigens including dsDNA, Sm-D, Rib-P, PCNA, U1-RNP (70, A, C), SS-A/Ro, SS-B/La, Centromere B, Scl-70, Fibrillarin, RNA Polymerase III, Jo-1, Mi-2, and PM-scl. The test results are expressed as ratio, with $>1.0$ considered positive. For ANA-IIF, the cut off for positive results was 1:40 or greater. Additionally, further testing for dsDNA and other extractable nuclear antigens (ENA) was undertaken on a subset of sera that were ANA-IIF+ or whenever there was discrepancy between the two methods.

Results: The overall agreement between the two methods was $84.2 \%$. Three hundread and eight (308) out of $1600(19.3 \%)$ samples tested positive by ANA-IIF positive as compared to $101 / 1600(6.6 \%)$ for the EliA-CTD assay. Additional testing showed that 105 samples were positive for ENA including dsDNA. Of those, 101 were EliA-CTD positive and 81 were ANA-IIF positive. By incorporating the ENA results, the calculated sensitivity and specificity for the EliA-CTD were $97.1 \%$ and $99.7 \%$ respectively with positive and negative predictive values for the EliA-CTD assay of $96.1 \%$ and $99.8 \%$, respectively. The corresponding sensitivity, specificity, positive predictive value (PPV) and negative predictive value (NPV) for the ANA-IIF assay at different dilutions is shown below:

\begin{tabular}{lcccc}
\hline Titer & Sensitivity (\%) & Specificity (\%) & PPV (\%) & NPV (\%) \\
\hline$\geq 1: 40$ & 77.7 & 84.8 & 26.0 & 98.2 \\
$\geq 1: 80$ & 60.3 & 95.3 & 32.4 & 98.4 \\
$\geq 1: 160$ & 57.4 & 97.4 & 41.3 & 98.4 \\
$\geq 1: 320$ & 46.5 & 98.7 & 48.8 & 98.5 \\
\hline
\end{tabular}

Conclusions: The new automated EliA-CTD assay shows superior sensitivity and specificity compared to the conventional labor intensive ANA-IIF. The EliACTD can be used as an upfront screening tool for connective tissue diseases. Depending on the clinical details, any EliA-CTD positive results could be reflexly followed by additional testing including ANA-IIF testing to elucidate the titer and pattern.

References:

[1] Hayashi N, Kawamoto T, Mukai M, Morinobu A, Koshiba M, Kondo S, Maekawa S, Kumagai S. Detection of Antinuclear Antibodies by Use of an Enzyme Immunoassay with Nuclear HEp-2 Cell Extract and Recombinant Antigens: Comparison with Immunofluorescence Assay in 307 Patients. Clinical Chemistry 2001; 47(9):1649-1959.

Disclosure of Interest: None declared

DOI: 10.1136/annrheumdis-2017-eular.2679

\section{AB1045 MACROPHAGE TARGETED POSITRON EMISSION TOMOGRAPHY (PET) FOR THE IMAGING OF INFLAMMATORY ARTHRITIS; AN IN VIVO AND IN VITRO INVESTIGATION OF TRANSLOCATOR PROTEIN (TSPO) TRACER UPTAKE}

N. Narayan ${ }^{1}$, H. Mandhair ${ }^{1}$, C. Coello ${ }^{2}$, A. Saleem ${ }^{2}$, A. Sabokbar ${ }^{1}$, P. Taylor ${ }^{1}$.
${ }^{1}$ Nuffield Dept of Orthopaedics, Rheumatology, Musculoskeletal Sciences, University of Oxford, Oxford; ${ }^{2}$ Imanova Centre for Imaging Sciences, London, United Kingdom

Background: TSPO targeted PET tracers are increasingly recognised as cellular imaging markers of macrophage infiltration, due to the high expression of TSPO on activated macrophages. Previous work demonstrated the ability of $\left[{ }^{11} \mathrm{C}\right] \mathrm{PK} 11195$ TSPO PET to detect subclinical inflammation in RA, and predict flare in both those with established RA and ACPA positive arthralgia. However, high background uptake of $\left[{ }^{11} \mathrm{C}\right] \mathrm{PK} 11195$ in bone, and inability of $\left[{ }^{11} \mathrm{C}\right] \mathrm{PK} 11195$ to detect lesions in AS has driven the investigation of newer TSPO tracers for the detection of inflammatory arthritis.

Objectives: Here, we present data confirming the ability of the TSPO tracer $\left.{ }^{11} \mathrm{C}\right] \mathrm{PBR} 28$ to detect and quantify synovitis in both RA and PsA, and in vitro work that assesses more fully what TSPO tracer accumulation in inflamed synovium actually reflects at a cellular level, especially considering TSPO is ubiquitously expressed.

Methods: 10 patients ( 5 with RA, 5 with PsA) with evidence of inflammation in one or both knees (as confirmed by clinical examination and US) and 4 healthy volunteers underwent PET/CT both knees using the TSPO tracer $\left[{ }^{11} \mathrm{C}\right] \mathrm{PBR} 28$. Arthritis patients underwent synovial biopsy of one knee within 7 days of scan. Healthy synovium was obtained from patients undergoing knee arthroscopy for ligamentous injury. Synovial tissue was stained for CD68, CD163 and TSPO. For in vitro work, human monocytes, lymphocytes and synovial FLS from RA patients were harvested, and macrophages differentiated from monocytes. RNA was extracted for PCR. Other cells underwent density centrifugation to extract the cytoplasmic cell fraction, and a radioligand binding assay with $\left[{ }^{3} \mathrm{H}\right] \mathrm{PBR} 28$ was undertaken, to assess tracer binding to TSPO in each cell type

Results: Tracer uptake correlated significantly with severity of inflammation on clinical examination and ultrasound, as did synovial sublining staining for CD68, TSPO and CD163 (see table 1). There was negligible staining for all stains in healthy control synovium. qPCR demonstrated highest TSPO mRNA in stimulated FLS (fold change 62.75 \pm 10.03 ) and M2 macrophages $(60.69 \pm 2.38$ ), with lymphocytes having the least TSPO expression. PBR28 saturation binding confirmed these findings at protein level (see graph 1).

\begin{tabular}{lccc}
\hline Tissue marker & \multicolumn{3}{c}{ Clinical synovitis severity } \\
\cline { 2 - 4 } & 1 (mild) & 2 (moderate) & 3 (severe) \\
\hline TSPO & $1.50 \pm 0.08$ & $2.19 \pm 0.19$ & $3.06 \pm 0.12$ \\
CD68 & $2.17 \pm 0.3$ & $2.42 \pm 0.21$ & $2.96 \pm 0.05$ \\
CD163 & $1.61 \pm 0.03$ & $2.19 \pm 0.1$ & $2.81 \pm 0.04$ \\
\hline
\end{tabular}

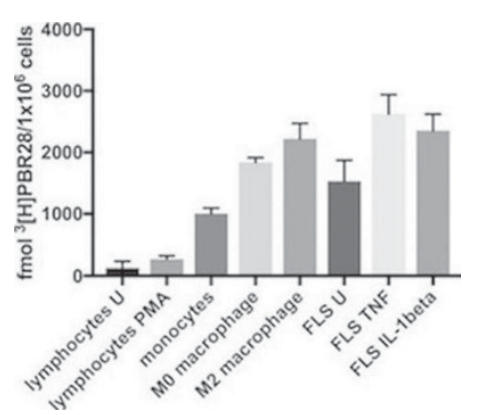

Conclusions: Our data demonstrates that the TSPO tracer PBR28 is capable of detecting and quantifying synovitis in RA and PsA. PBR28 tracer uptake correlates with macrophage marker staining, but not with fibroblast marker staining in our patient cohort. mRNA and protein data demonstrate, however, that there is a similar expression of TSPO in activated macrophages and activated FLS, hence TSPO tracer accumulation is as likely to represent FLS activation as it is macrophage activation.

References:

[1] Gent $Y Y$ et al. Macrophage positron emission tomography imaging as a biomarker for preclinical rheumatoid arthritis: findings of a prospective pilot study. Arthritis Rheum 2012; 64:62-6.

[2] Gent YYJ et al. Subclinical synovitis detected by macrophage PET, but not $\mathrm{MRI}$, is related to short-term flare of clinical disease activity in early RA patients: an exploratory study. Arthritis Res Ther 2015; 17:266.

Disclosure of Interest: None declared

DOI: 10.1136/annrheumdis-2017-eular.1838

\section{AB1046 COULD SERUM TWEAK LEVEL BE AN INDICATOR OF SUBCLINICAL ATHEROSCLEROSIS IN RHEUMATOID ARTHRITIS?}

M. Ucer ${ }^{1}$, N. Yilmaz ${ }^{2}$, B. Cengiz Elcioglu ${ }^{3}$, T. Sahin ${ }^{3}$, P. Gun Atak ${ }^{4}$, S. Yavuz ${ }^{2}$ ${ }^{1}$ Internal Medicine; ${ }^{2}$ Rheumatology; ${ }^{3}$ Cardiology; ${ }^{4}$ Biochemistry, Istanbul Bilim University, Istanbul, Turkey

Background: TWEAK is a type 2 transmembrane glycoprotein of TNF family that has multiple functions such as angiogenesis, regulation of tissue production- 